\title{
STUDIES OF CALCIUM AND PHOSPHORUS METABOLISM
}

XII. The Effect of the Ingestion of Acm-producing Substances

BY RAY F. FARQUHARSON, ${ }^{1}$ WILLIAM T. SALTER, DOROTHY M. TIBBETTS AND JOSEPH C. AUB

(From the Aredical Clinic of the Massachusetts General Hospital, Boston)

(Received for publication November 26, 1930)

In the course of our studies in calcium metabolism evidence has steadily accumulated that the metabolism of acid-producing substances plays an important rôle in influencing the assimilation and excretion of calcium. This effect, however, has not been adequately studied in man, and in other studies of calcium exchange the potential acidity or alkalinity of foods and medication has largely been neglected.

It is the purpose of the present investigation to follow the effect of food-stuffs and inorganic salts on calcium metabolism with relation to their potential acidity (after oxidation) referred to the hydrogen ion concentration of the blood.

Studies in rickets for some time have indicated the importance of acidity to the assimilation and storage of inorganic salts in bone. Thus, McClendon (1) noted that the addition of alkali to a diet increased its power to produce rickets and, conversely, Zucker, Johnson, and Barnett (2) reported that the change in acidity of diets from the alkaline toward the acid side of neutrality might result in healing of the rachitic lesions.

Much work, too, has been done upon the effect of administered acid on the mineral excretion. The experiments of Givens and Mendel (3) and of Givens (4) upon the effect of base and acid on the general metabolism tended to minimize variations in calcium excretion resulting from this factor. Subsequently, Goto (5), using rabbits, demonstrated depletion of the skeleton by repeated doses of hydrochloric acid. Lamb and Evvard (6) demonstrated increased urinary calcium

${ }^{1}$ Alexander McPhedran Research Fellowship in Clinical Medicine, University of Toronto. 
excretion in pigs following the administration of mineral acid, but not after feeding oxidizable organic acids. Shohl and Sato (7) showed that the feeding of hydrochloric acid decreased the storage of calcium by growing children, and demonstrated the reverse effect of sodium bicarbonate. These effects were also noted by Zucker (8).

The fate of inorganic acid in animals has been followed by Fiske and Sokhey (9) and by Fiske and other collaborators (10). Stehle and McCarty (11) extended the former's work on ingested hydrochloric acid to man. Bogert and Kirkpatrick (12) specifically studied the effect of acid-forming and base-forming diets upon calcium metabolism in man, but their interesting experiments were confused by lack of constant calcium intake throughout. All of these investigators found that an increase in calcium excretion followed administration of excess acid.

Less importance has been attached to endogenous acid metabolites. Nevertheless, Nelson (13) has pointed out the effect of ketogenic diets on calcium metabolism. Her results confirm the earlier work of Sawyer, Baumann, and Stevens (14) on the effects of ketosis. These studies, together with an investigation on the inorganic salt metabolism in diabetic acidosis (15), have furnished ample evidence that acid metabolites, which arise from body tissues, are likewise important in regulating or influencing calcium excretion. The classical work of Benedict (16) on subject $\mathrm{L}$, during the latter's thirty-one-day fast, has already been mentioned from this point of view (17).

The influence of various hormones upon calcium metabolism has already engaged the attention of those interested in this field, but the mechanism by which the minute amounts of these substances produce their specific effects upon bone metabolism remains to be solved. The same is true of (exogenous) accessory food substances. It is very important, therefore, in view of the gross changes in body tissues which these specific chemical regulators produce, to understand the effect which endogenous acid catabolites may exhibit. The excessive breakdown of protein in hyperthyroidism is a case in point.

In order to establish the quantitative significance of this factor, it was first necessary to determine the basal level of endogenous calcium metabolism in each (human) subject studied while taking a low calcium diet. Thereafter, acid- or alkali-producing substances could be added 
and their effects noted as superimposed upon the basal stream of calcium excretion.

In this work little stress will be laid upon the calcium and phosphorus content of the blood serum because these values showed little effect resulting from change in diet. The height of these levels, in normal subjects at least, had essentially no influence upon the calcium stream. Much more emphasis has been placed upon the excretion of acid in the urine because a consideration of this value (or of its components) offers one of the best guides to a quantitative interpretation of calcium balances. This is the more important because, as will be demonstrated, the excretion of fecal calcium has remained essentially constant despite the various dietary changes upon which these experiments are based, wherefore it may be concluded that variations of bowel activity including increased excretion of calcium or deficient assimilation (such as have been reported in studies on rickets or in ergosterol feeding) may be neglected in this work.

\section{EXPERIMENTAL PROCEDURE AND METHODS}

The general procedure was essentially that described in a former paper (18). Most of the patients were given a constant diet low in calcium (about $100 \mathrm{mgm}$. daily) and moderately low in phosphorus, but adequate with respect to other inorganic salts, fat, carbohydrates, protein, total calories, and vitamins (18). In one patient, the effects. of acid administration were observed first on this low calcium diet and then on a diet containing about $700 \mathrm{mgm}$. Ca per day, which was sufficient to give a definite positive calcium balance. In all cases on a given diet the same articles of food were taken each day so that whatever errors in calculation might exist would remain as nearly constant as possible throughout. The basal diet was so constituted as to give a neutral inorganic residuum when oxidized,-such a diet being described as a potentially neutral diet. Except in experiments in which the effect of an acid diet was studied, the same potentially neutral diet was used throughout the whole period of observation of each patient.

Although by calculation these diets were potentially neutral, nevertheless, in all cases the patients excreted an appreciable amount of "total acid" as judged by ammonia and titratable acidity of the 
urine. The "total acid"2 output was highest in a patient whose stools were very large, due to deranged fat absorption and it was found that the titratable alkalinity of the fecal ash (which probably neutralized fatty acids in large measure) was about equal to the ammonia plus titratable acidity of the urine. For different persons on the same type of neutral diet there was considerable variation in the "total acid" output of the urine. It is probable that for a given diet this "total acid" output varies with the amount of excess alkali in the fecal ash. From the point of view of acid-base metabolism, the potential acid effect of the diet in a given case can be gauged qualitatively by relative changes in the "total acid" output of the urine. Accordingly, the ammonia and titratable acidity of the urine were measured daily in all subjects studied.

Specimens for general purposes were collected and mixed in threeday periods as described elsewhere (18). Care was taken to obtain stools regularly and constipation was prevented by frequent small doses of cascara. In many cases the stools were approximately equal in weight and inorganic constituents. Occasionally, however, a very large stool in one period followed an unusually small one for the preceding period and it was obvious that there had been a delay in evacuation. In one instance (BE-Case IV) a definite constipation with small hard stools persisted for about three periods in which fecal inorganic content, including calcium, was very low. In the succeeding periods there was no unusually large fecal excretion of calcium or other inorganic salts, thus indicating that there had been an increased absorption from the large bowel. It was also noticed in some other cases, not reported in this paper, that the calcium content of the feces tended to be higher on changing to a diet with great fecal residue and lower when residue was small. Except in the instance already noted, these factors were well controlled during this investigation.

\section{METHODS}

All determinations were done in duplicate and repeated if satisfactory checks were not obtained. The methods used for titratable

2 Throughout this paper the term "total acid" output refers to the sum of ammonia plus titratable acidity in the urine. The term "titratable acidity" means the titratable acidity minus $\mathrm{CO}_{2}$ as described in Paper VIII of this series, J. Clin. Invest., 1931, x, 187. 
acidity, ammonia, phosphorus, chloride, and total base were those of Henderson and Palmer; Folin; Fiske and Subbarow; Van Slyke; and Fiske respectively, with certain minor modifications as fomerly described (18). Calcium determinations in blood, urine, and feces were made by Fiske's method (19). This method has proven most satisfactory under all conditions. The duplicates seldom varied as much as 2 per cent and the calcium could be reprecipitated and redetermined with nearly identical results. Inorganic sulphate only was determined (Tables 1,2 and 3) by Fiske's benzidine method.

\section{EXPERIMENTS AND RESULTS}

The first experiments were planned to show the relative effects of ingestion of (1) a potentially acid diet, (2) varying quantities of alkali and (3) varying amounts of $\mathrm{NH}_{4} \mathrm{Cl}$ on the calcium and phosphorus metabolism. In some instances dietary changes were made after too short an interval as we had not at that time realized the necessity of longer control periods and of the length of time required before a steady state could be established. The general plan in the first three cases was very similar and they are, therefore, presented together.

Case I (AN, aged 16, weighing 34 kilos) suffered from a marked structural scoliosis. After a 15 day control period on a neutral, low calcium diet and prior to operative interference he was placed at complete rest in a plaster shell for several weeks. Two periods were allowed for control in this state of inactivity, following which the diet was changed to one of about $700 \mathrm{cc}$. N/10 potential acidity per day for three periods; then while still at rest and on the former neutral control diet, the effect of ingestion of $\mathrm{NH}_{4} \mathrm{Cl}$ and $\mathrm{NaHCO}_{3}$ was observed. Six months after a spinal fusion for correction of his deformity he was readmitted and the effect of ingested $\mathrm{NH}_{4} \mathrm{Cl}$ once more observed.

Case II (DA), aged 37, weighing 58 kilos, and Case III (ST), aged 46, weighing 51 kilos, were both recovering from lead poisoning. A similar series of experiments were made as on AN, the details and results of which are presented in tables 2 and 3 .

Later the effect of graded doses of $\mathrm{NH}_{4} \mathrm{Cl}$ was observed for longer intervals, first on a low and then on a higher calcium diet on a patient, (BE) aged 58, weighing 55 kilos, who suffered from chronic sciatic neuritis. Results are presented in table 4.

All these patients cooperated willingly, took the diet cheerfully and completely and seemed happy throughout the observation. 


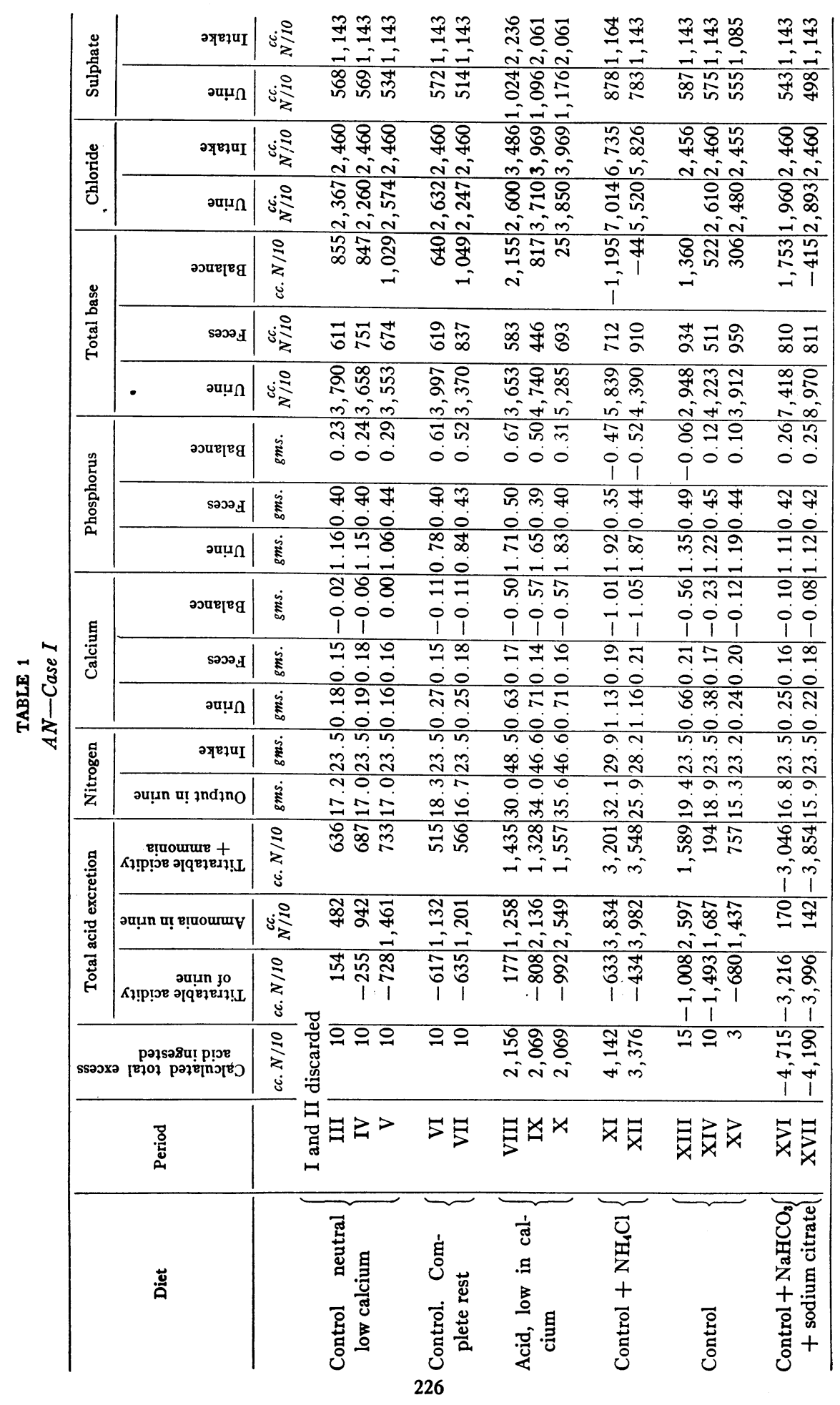




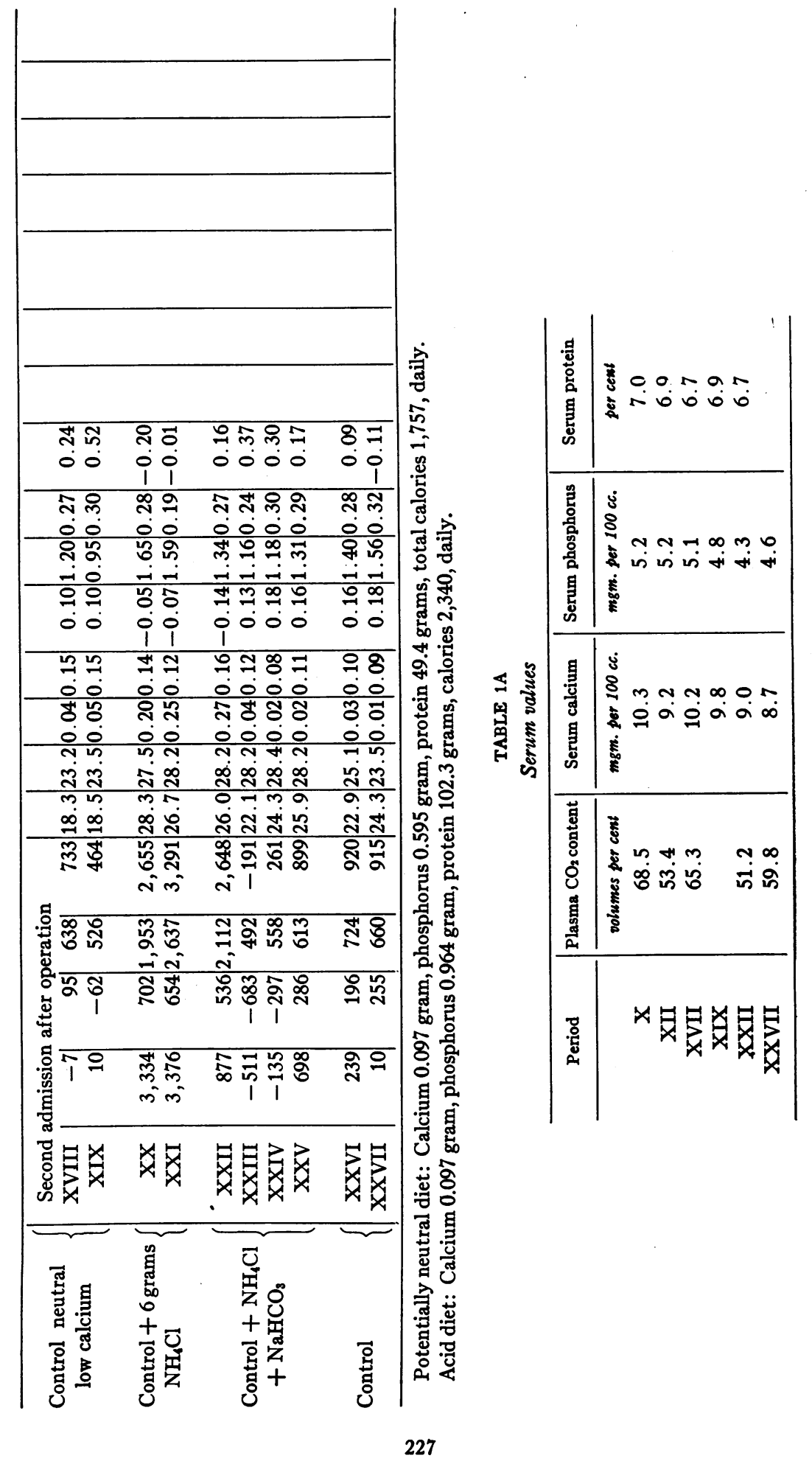




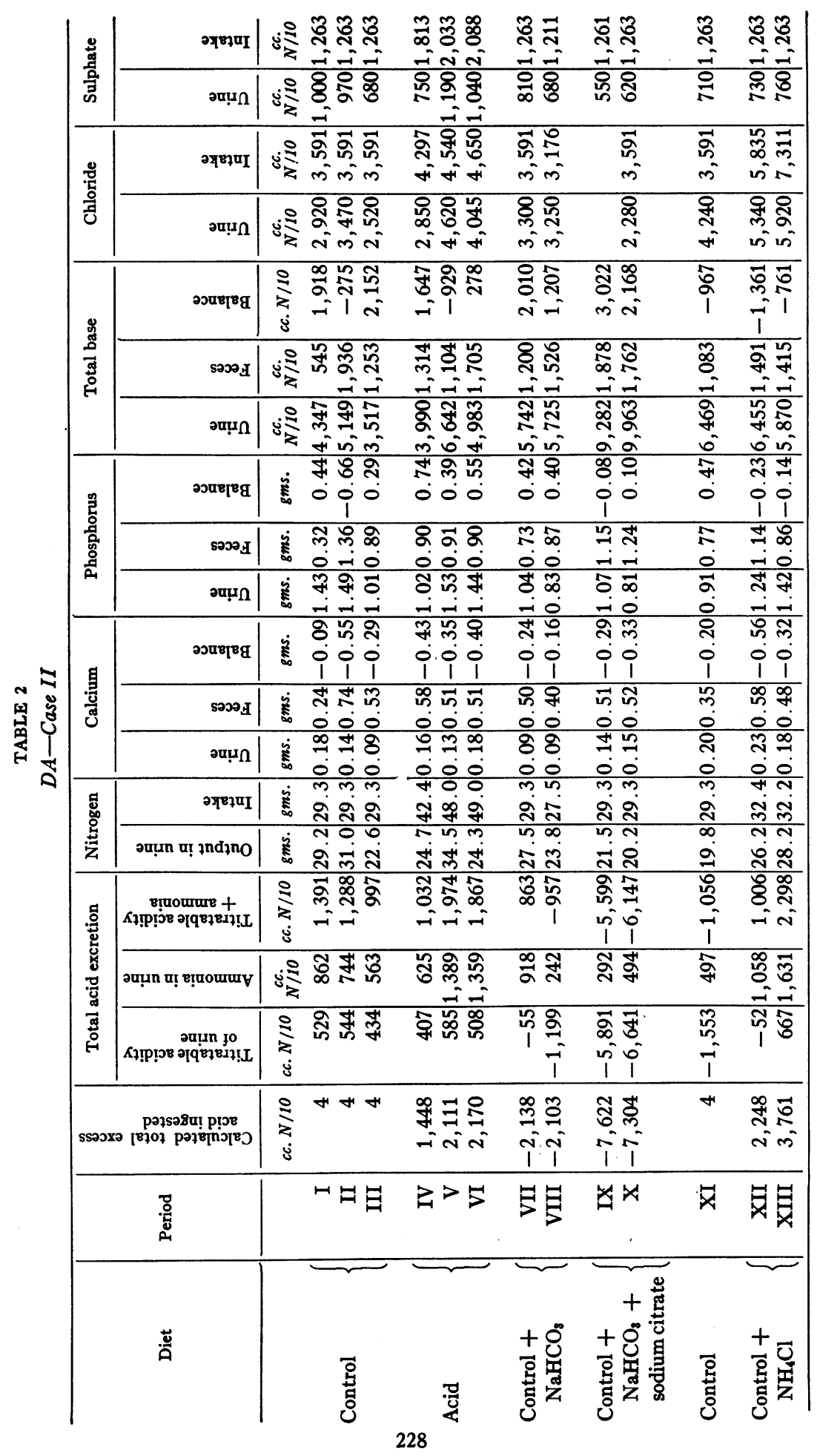




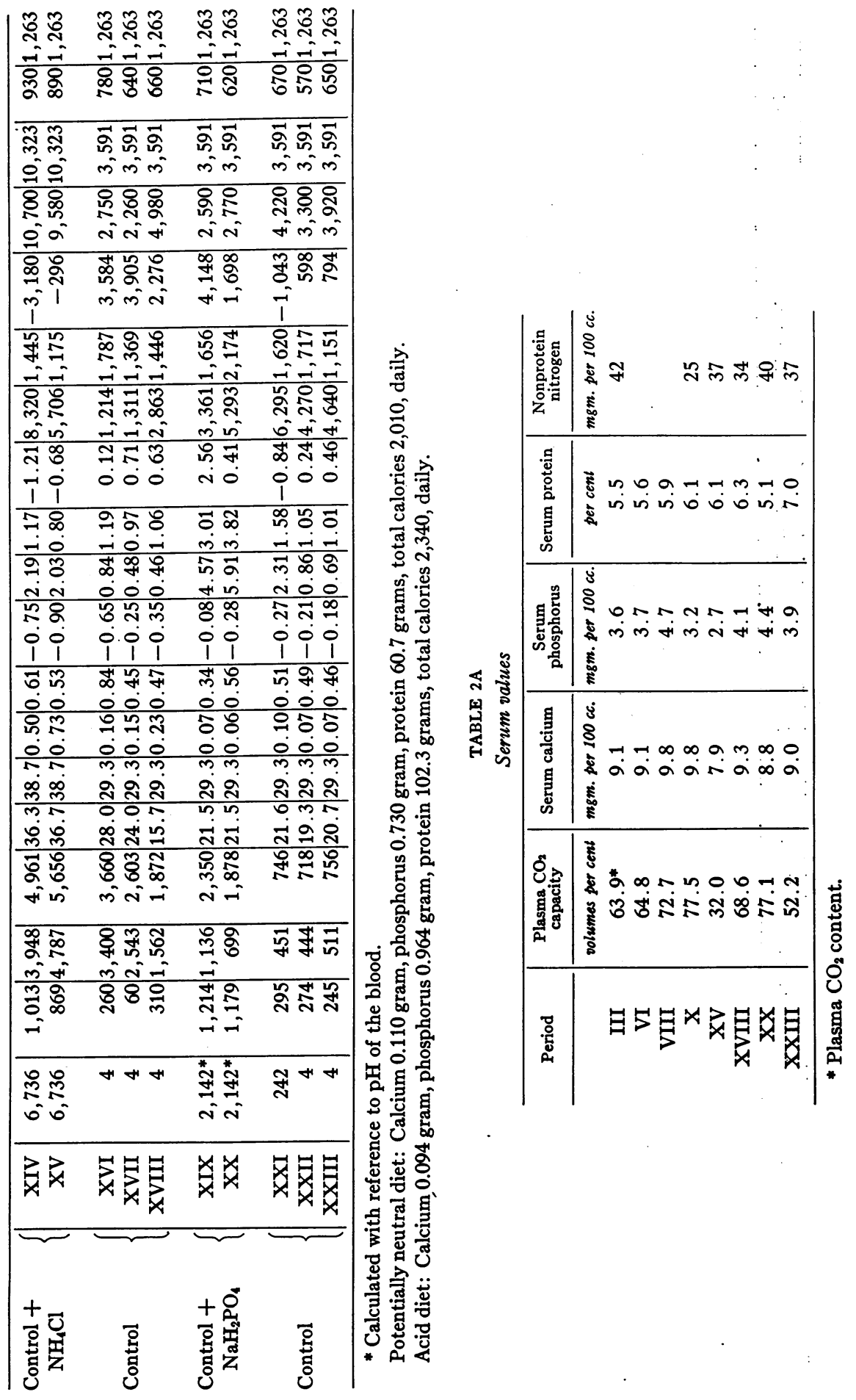




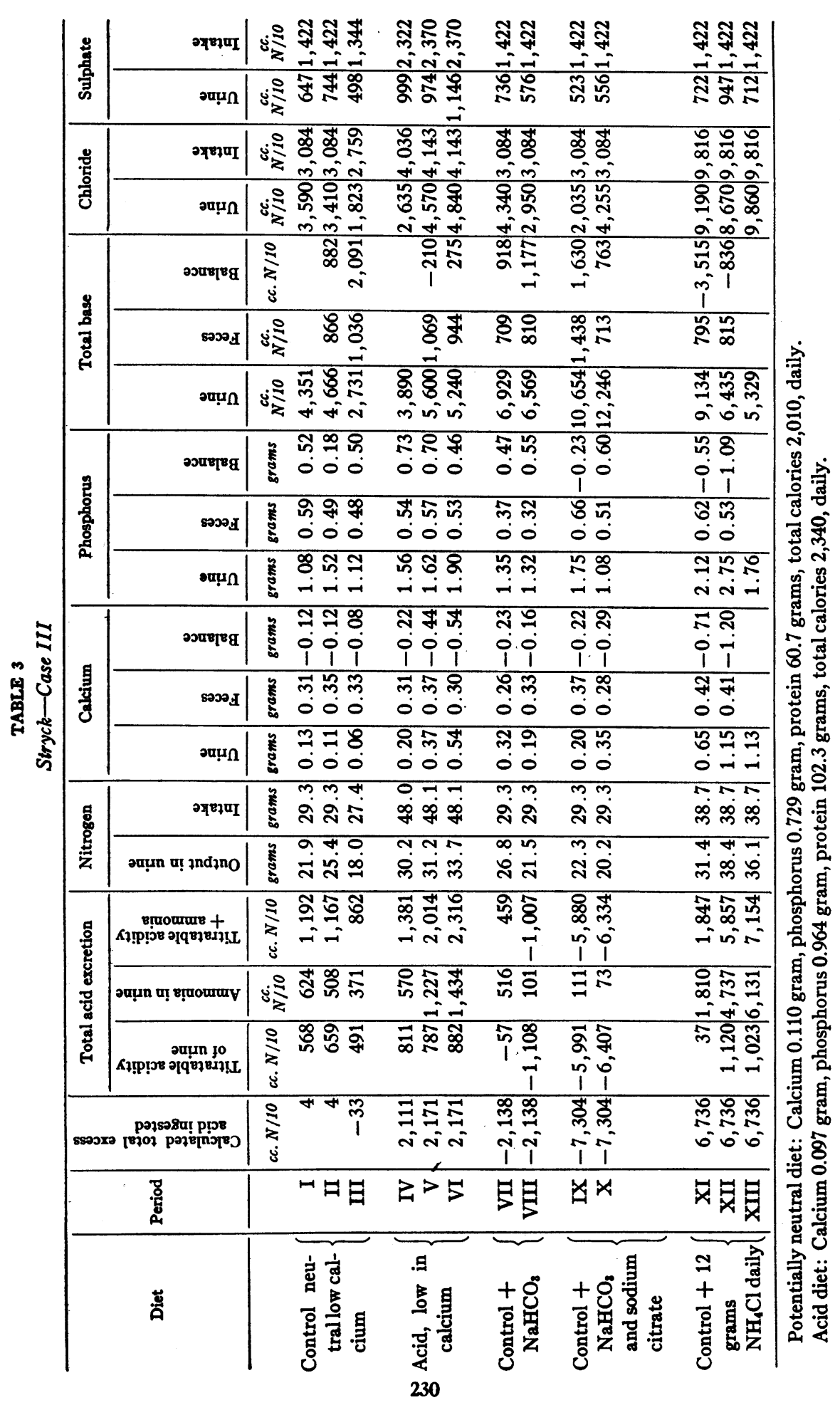




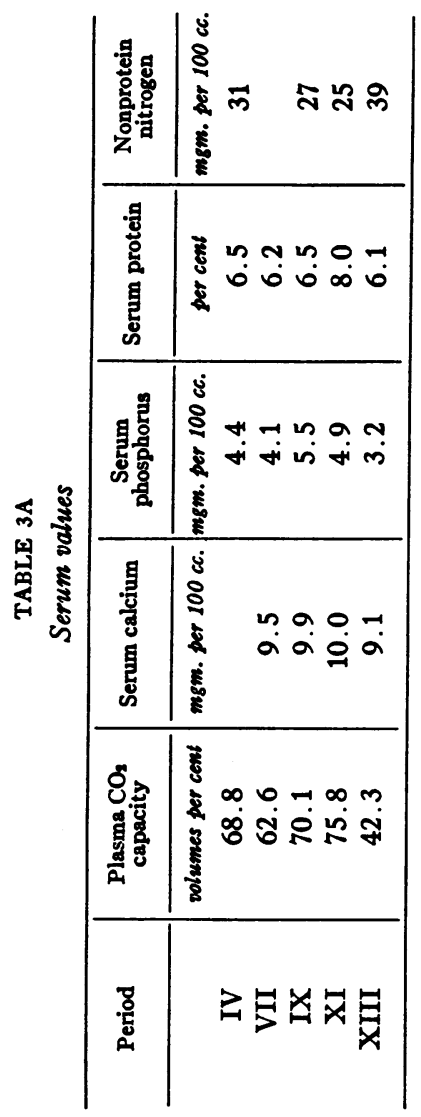




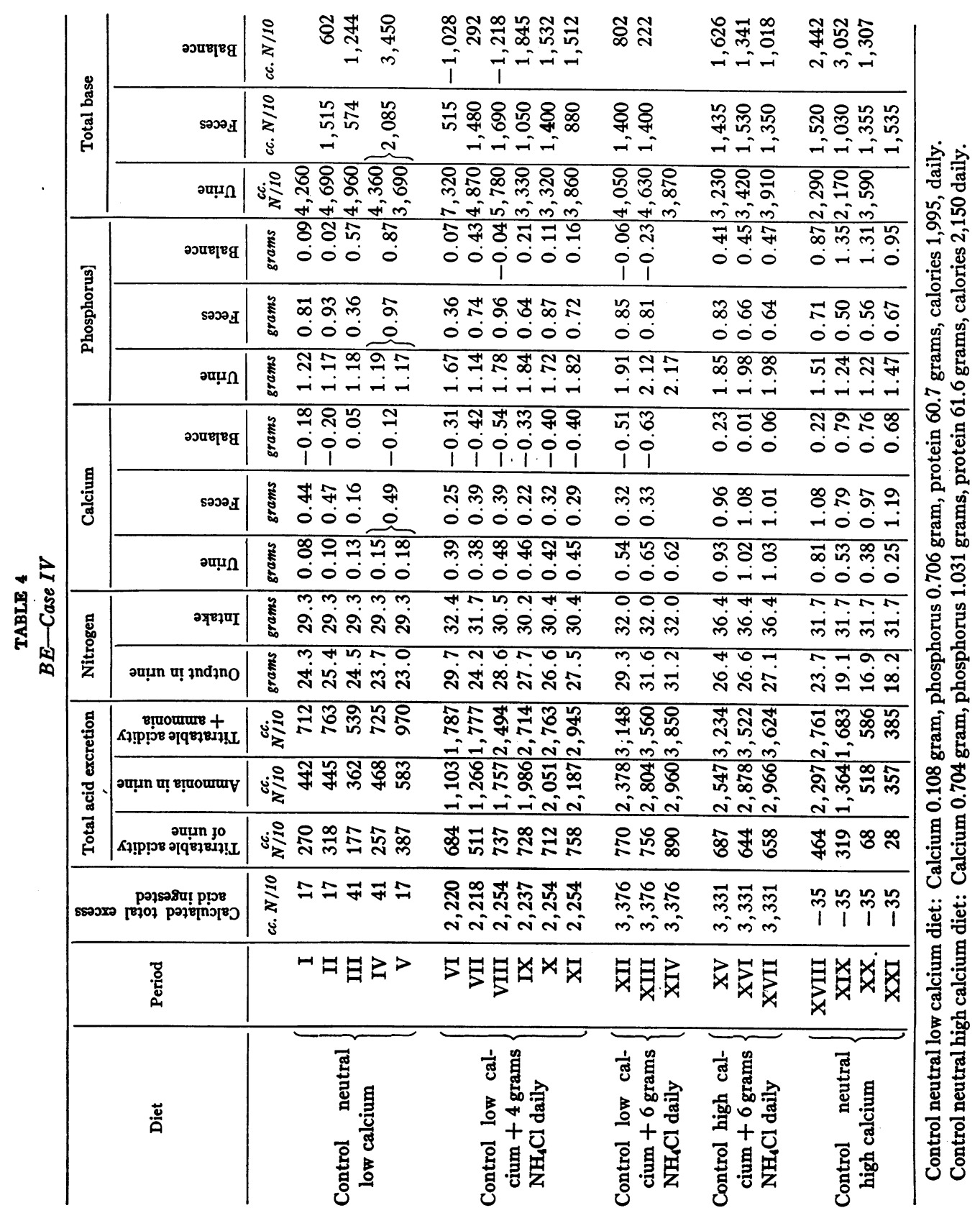




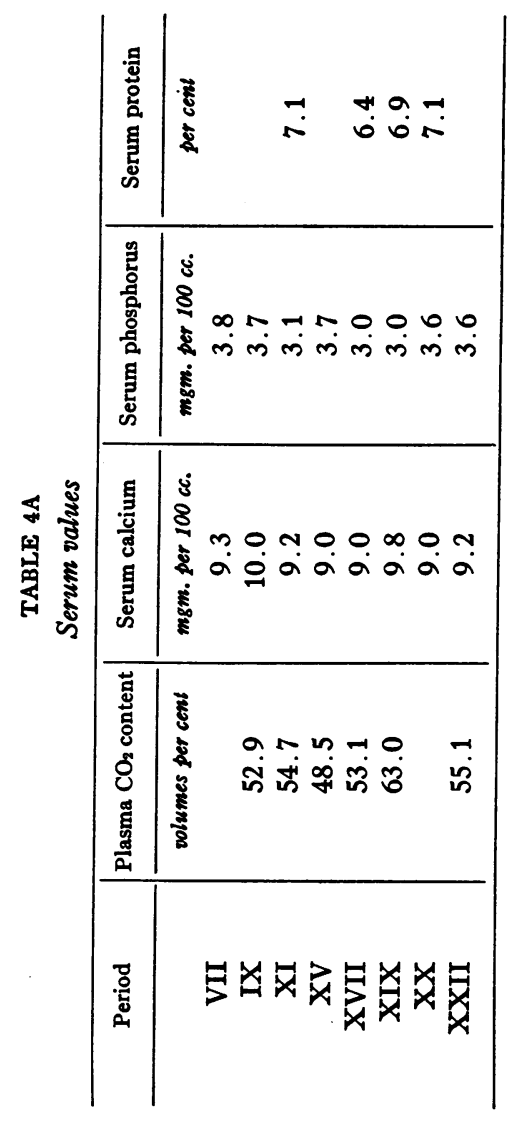




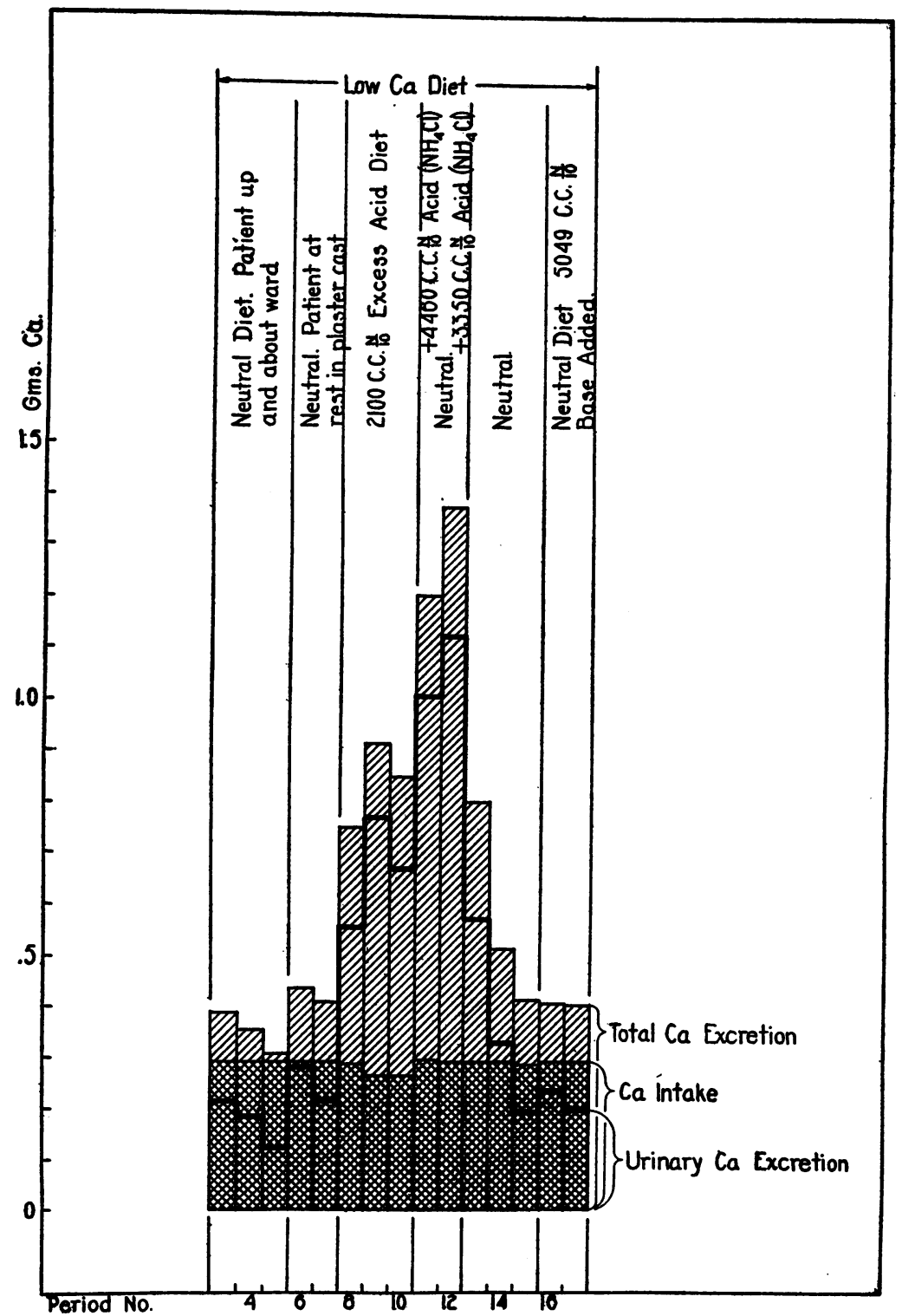

Fig. 1. Calcium Excretion per Three-day Period

Calcium excretions per three-day period are divided into fecal and urinary components. The calcium intake, as shown, remains nearly constant. The potential acidity of the ingesta (including both food and medication) is indicated at the top of the figure. 


\section{COMMENT}

On ingestion of a potentially acid diet or of $\mathrm{NH}_{4} \mathrm{Cl}$ there was in all cases a prompt though gradual increase in the excretion of calcium in the urine, which reached a maximum usually in the second or third period and then remained at this high level for the whole duration of acid administration. In the after-periods the urine calcium fell gradually, requiring from 6 to 9 days to return to the basal level. It was notable that under the conditions of these experiments the fecal calcium remained remarkably constant, showing no appreciable change even when the calcium content of the urine was increased tenfold.

The effect of ingestion of an acid diet was essentially similar to that of ingested inorganic acid, subject to certain modifications. Since the protein of the food contributes much to the excess acid of this diet, the "acid effect" depends in large measure on the nitrogen balance. In the case of DA (Case II, periods IV, V, and VI) for instance, on the acid diet there was a gross positive nitrogen balance and the acid effect as judged by the "total acid" excretion of the urine was correspondingly lessened. His urinary calcium excretion, accordingly, did not increase on ingestion of this diet to the same extent as did that of AN and ST, who utilized most of the protein fed as fuel. It may be noted, however, that in none of the three was the acid effect of the diet, as judged by the ammonia plus titratable acidity of the urine, quite as great as calculated. The response of the urinary calcium to the acid diet and administration of $\mathrm{NH}_{4} \mathrm{Cl}$ in $\mathrm{AN}$, (Case I) is graphically represented in figure 1 . This shows clearly the great increase that occurred in response to both types of acid administration.

That the effect of the acid diet was not due to any specific influence of the greater protein content apart from its potential acid value has been demonstrated by other experiments (20) in which it was shown that when sufficient $\mathrm{NaHCO}_{3}$ was administered to neutralize the acid effects of a high protein diet, no increased excretion of calcium occurred. Only about one-fourth of the calculated excess acid in these diets was due to an increased phosphorus content.

\section{The quantitative response to acid ingestion}

There are some interesting observations with regard to the actual quantitative increase in calcium excretion in response to the ingestion 
TABLE 5

Response of urinary calcium excretion to ingestion of $\mathrm{NH}_{1} \mathrm{Cl}^{*}$

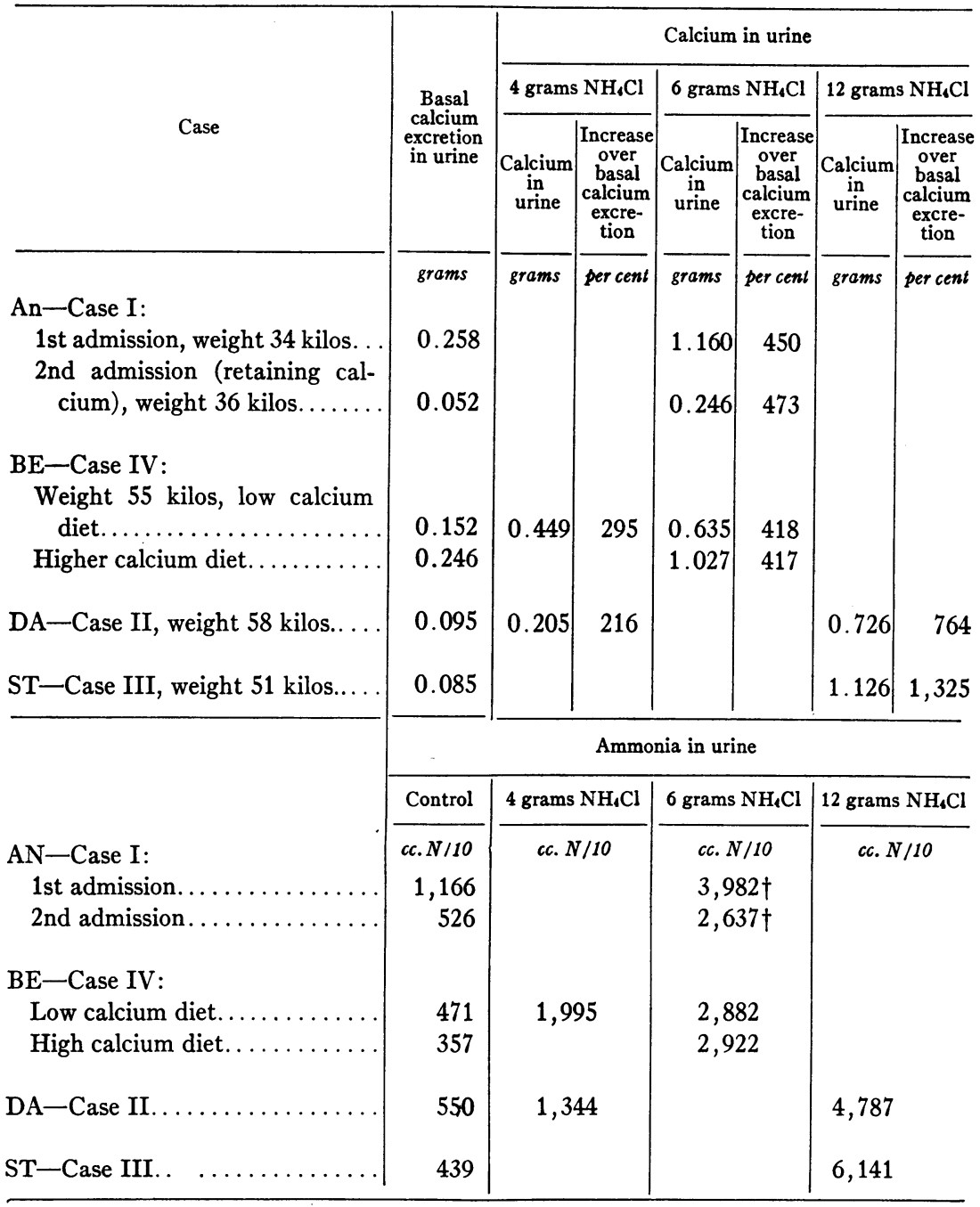

* Transitional period omitted in making calculations.

$\dagger$ On this first admission, there was an actual overproduction of ammonia so that the urine was alkaline throughout. The corresponding values for "total acid" excretion are 3,548 and 3,290 respectively. 
of acid. For instance, on the first admission of AN (Case I, scoliosis) the urinary calcium was moderately high, there was a negative calcium balance and on ingestion of 6 grams of $\mathrm{NH}_{4} \mathrm{Cl}$ per day the urinary calcium increased fourfold till it was over 1 gram per period. On his second admission, 6 months after an orthopedic operation, the urinary calcium was low and even on the low calcium intake there was a definite positive calcium balance. The calcium metabolism in short was essentially like that of a growing child. On daily ingestion again of 6 grams of $\mathrm{NH}_{4} \mathrm{Cl}$ the "total acid" of the urine increased to about the same level as on the former admission. The calcium output in the urine, however, although it increased fourfold did not exceed 0.25 gram and was in fact about the same as that of the basal periods of his first admission. It seems probable that, under the altered metabolic conditions following the spinal fusion but on the same calcium intake, his body was retaining more calcium and allowing only a small amount to be discharged in the outflowing stream. Yet, it is interesting that the same amount of $\mathrm{NH}_{4} \mathrm{Cl}$ in the two instances gave rise to about the same proportionate increase of urinary calcium.

In looking over the rest of the data of different "normal" subjects from this point of view, it appears that although there was a great difference in the basal level of urinary calcium excretion and also great variation in the amount of extra calcium excreted in response to a given dose of $\mathrm{NH}_{4} \mathrm{Cl}$, yet in each case the increase in the output of calcium was roughly proportional to the initial basal level and to the amount of $\mathrm{NH}_{4} \mathrm{Cl}$ ingested. This is well shown by data collected in table 5.

Thus, in $\mathrm{BE}$ (Case IV) on ingestion of 6 grams of $\mathrm{NH}_{4} \mathrm{Cl}$ daily the urinary calcium was 0.635 gram on a low calcium diet, (periods XIII and XIV); and 1.03 gram on a high calcium diet (periods XVI and XVII). This represents an increase of about 400 per cent above the control level for the corresponding diet in each instance. This proportionate increase is of essentially similar magnitude to that which occurred in AN on each admission in response to the same amount of $\mathrm{NH}_{4} \mathrm{Cl}$. The response to 4 grams $\mathrm{NH}_{4} \mathrm{Cl}$ in $\mathrm{DA}$ (Case II, periods $\mathrm{XII}$ and XIII) was a 216 per cent increase in urinary calcium, and in BE (Case IV, periods VIII-XI) a 295 per cent increase although in 
BE the actual increase in grams of calcium in the urine was more than double that which occurred in DA.

In figure 2, the relation of the percentage increase of calcium excreted in the urine to the amount of $\mathrm{NH}_{4} \mathrm{Cl}$ ingested per kilo is graphically represented. This series of points approaches the form of a smoothcurve.

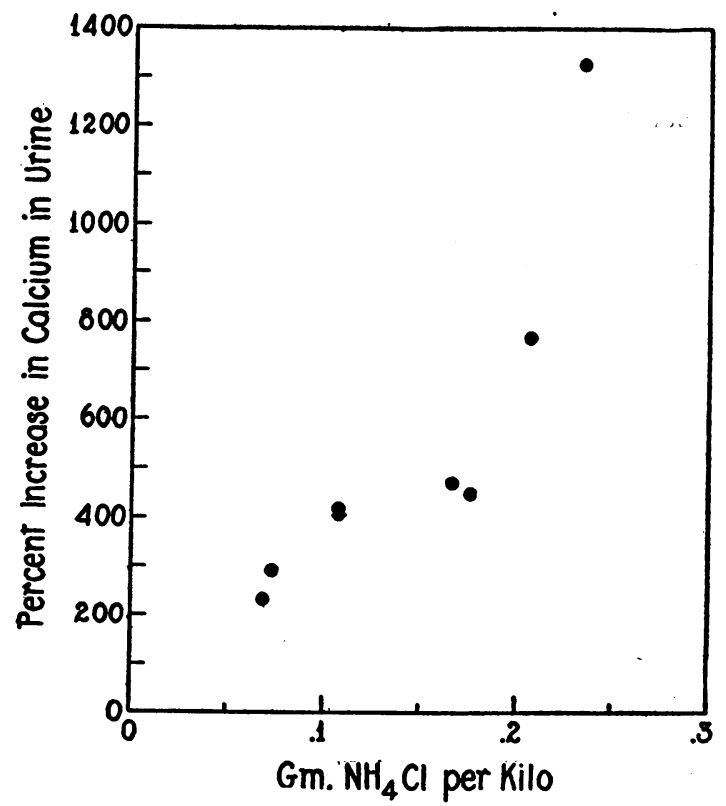

Fig. 2. The Effect of Ammonium Chloride Ingestion upon Urinary Calcium Excretion

The increase in urinary calcium excretion over the basal level is expressed as a percentage. The corresponding amounts of ammonium chloride fed are given in milligrams per kilo of body weight.

It may be that the factors tending to increase calcium excretion as a result of ingestion of $\mathrm{NH}_{4} \mathrm{Cl}$ are limited by the factors already regulating the urinary output of calcium. The result, therefore, might be viewed as a proportionate increase of the outflowing stream, rather than as a quantitative response in calcium excretion to a definite amount of acid ingested. 
The rôle of the increased calcium excretion in neutralizing excess acid ingested

Although the ingestion of excess acid has a pronounced effect on the urinary calcium excretion and on the calcium balance, nevertheless,

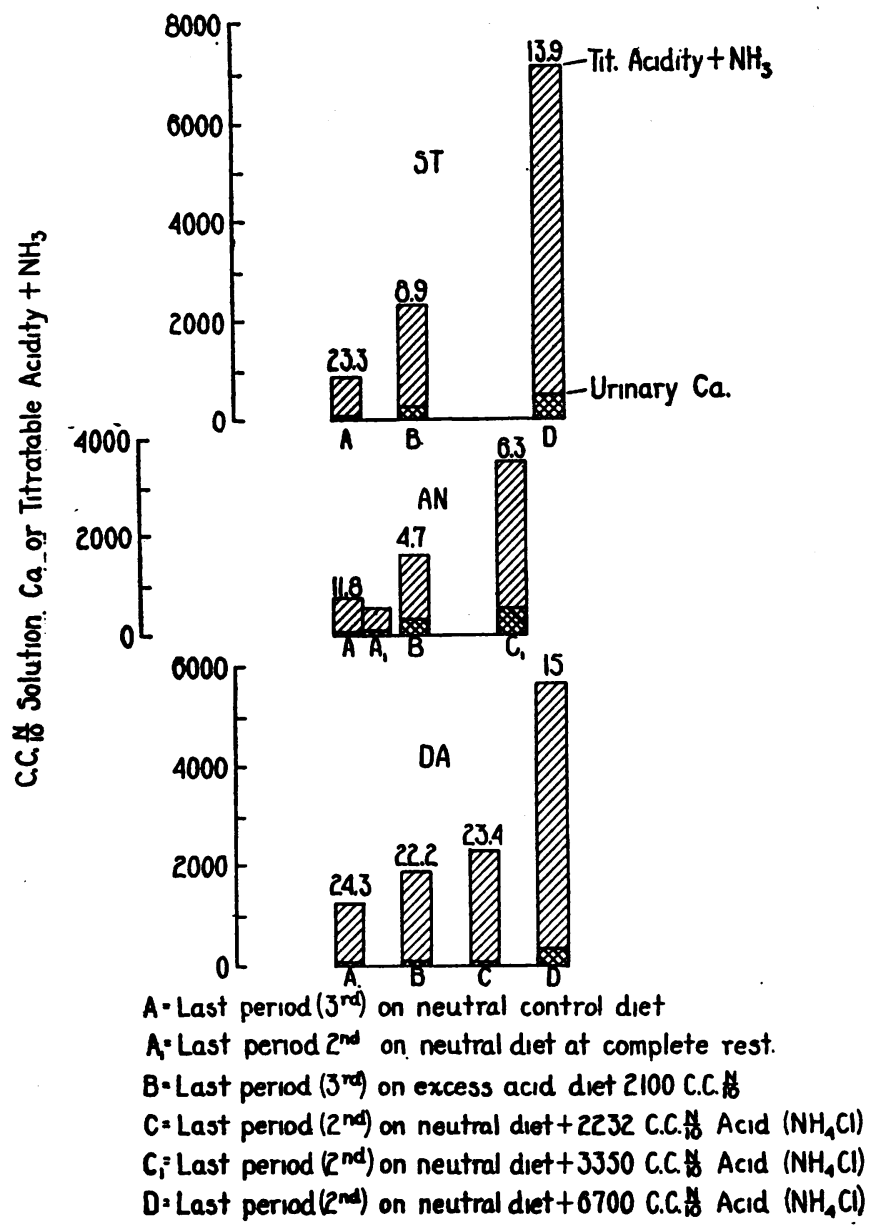

Fig. 3. The Efrect of Acdo Diets and Acid Salts upon the Act and Caicium EXCRETION IN THE URTNE

the increased calcium of the urine plays but a small part in neutralizing the excess acid eliminated. There is, on the other hand, a great 
increase in the ammonia, which bears the brunt of the burden, and usually a very definite increase in the titratable acidity of the urine. The relation of the total calcium output in the urine to the sum of the ammonia and titratable acidity, in the various observations on our first three patients is represented in figure 3. From a glance at this chart it is obvious that the proportion of calcium to the ammonia and titratable acidity is small. Even in acidosis when, as in DA, (column D), the plasma $\mathrm{CO}_{2}$ combining power had fallen to 32 volumes per cent, the greatly increased calcium output of the urine was relatively insignificant when compared with the extent of the ammonia and titratable acidity. Moreover, in our cases, (e.g., BE Case IV, periods IX-XI, XIV) the increase in ammonia and titratable acidity in response to ingestion of $\mathrm{NH}_{4} \mathrm{Cl}$ soon reached a value that was almost equal to that of the total excess acid ingested.

Even if all the calcium excreted could act as alkali, its rôle in neutralizing acid would be relatively insignificant. It is probable, however, that some of the extra calcium, when excreted, is accompanied by acid radicles with which it was associated in the body stores whence it originated, whether from soft tissue or from bone. This consideration would tend further to minimize the availability of calcium as a reserve alkali.

It may further be pointed out that when a neutral diet of higher calcium content was taken with the simultaneous ingestion of 6 grams of $\mathrm{NH}_{4} \mathrm{Cl}$ per day, as in $\mathrm{BE}$ (Case IV, periods XV-XVII) the greatly increased amount of calcium in the urine failed to reduce the excretion of urinary ammonia.

Our results, showing the small part played by calcium in neutralizing excess acid of the urine, are similar to those obtained by Gamble, Ross, and Tisdall (21) in fasting children.

The relation of the increased calcium excretion to the acidity of the urine and ammonia production

The "total acid" excretion of AN (Case I) was unusual in that so much ammonia was produced that the urine remained alkaline in reaction even when large amounts of excess acid were ingested. In spite of the fact that the urine remained alkaline, great increases in urinary calcium excretion followed upon ingestion of acid diets and of 
$\mathrm{NH}_{4} \mathrm{Cl}$. The calcium excretion, in fact, seemed to vary with the total amount of excess acid eliminated, and especially with the amount of ammonia excreted, irrespective of the reaction of the urine. This peculiar overproduction of ammonia is discussed at greater length in another paper (22).

In response to ingestion of excess acid except in the case of acid phosphate, ammonia production played a much greater rôle than did increased titratable acidity of the urine. Ammonia production increased promptly but gradually as did the calcium of the urine, remained high throughout the period of acid ingestion, and like the calcium fell off gradually in the after period. The titratable acidity on the other hand usually increased to its maximum more rapidly than did either ammonia or calcium and on discontinuing administration of excess acids it fell off abruptly to levels below those of the control period. The ingestion of acid phosphate, however, caused a great increase in titratable acidity of the urine but no appreciable effect on either ammonia or calcium (20).

It is probable that increased ammonia production and increased urinary calcium excretion are separate responses to a common cause and not directly interdependent. Both are greatest when as in the cases of DA (Case II, periods XIV and XV) and ST (Case III, periods XII and XIII) there is a definite acidosis with low plasma $\mathrm{CO}_{2}$. Neither are materially affected by ingestion of $\mathrm{NaH}_{2} \mathrm{PO}_{4}$, which (being readily excreted in an acid urine) places little strain on the mechanism that regulates the acid-base balance.

\section{The excretion of calcium and fixed base}

In response to administration of large doses of $\mathrm{NH}_{4} \mathrm{Cl}$ (e.g. ST, Case III, periods XI-XIII) there is a prompt rise in the excretion of total fixed base in the urine, which in our cases was maximal in the first period of increased acid administration. This increase in excretion of total fixed base is associated with a rapid loss of body weight (water and electrolytes) which has been well discussed by Gamble, Blackfan and Hamilton (23). There is thus seen to be a very great difference between the response in total fixed base excretion and in that of calcium. The output of total fixed base rises rapidly with the initial diuresis and loss of weight and then falls toward its former level. 
Immediately on cessation of $\mathrm{NH}_{4} \mathrm{Cl}$ the excretion of fixed base falls temporarily to much below that of the control periods while the body retains water and gains in weight. The calcium excretion, on the other hand, rises gradually in response to ingestion of acid, requiring a few days to reach its maximal level at which it remains while excess acid is administered; then falls off slowly, taking several days to return to the control level.

That the amount of calcium of lost body fluids was quite insufficient to account for extra calcium eliminated in fasting children was shown by Gamble (21). Similarly, in our cases the calcium of the body fluids lost in diuresis is insignificant when compared with total extra excretion of calcium in the urine. Moreover, as just noted, the diuresis was over before the calcium excretion reached its maximum and in the after-period there was no compensatory retention of calcium.

\section{The effect of ingestion of $\mathrm{NH}_{4} \mathrm{Cl}$ on the nitrogen metabolism}

In most of our subjects the ingestion of $\mathrm{NH}_{4} \mathrm{Cl}$ resulted in a greater increase in the nitrogen of the urine than could be accounted for by the increased intake. This was associated with an increase in excretion of inorganic sulphate. In the after periods there was usually some nitrogen retention. This increased output of nitrogen was not always associated with a loss of body weight. It is obvious that nitrogen, administered as a potentially acid ammonium salt does not spare protein metabolism, but actually results in loss of nitrogen, probably from the deposit nitrogen of the organism.

\section{The relation of the calcium and phosphorus balances}

In all cases, when the excretion of calcium was greatly increased there was also a definitely increased output of phosphorus: when an appreciable amount of calcium was retained, phosphorus was also retained. If one calculates the phosphorus equivalent of the extra calcium excretion on the basis of the proportion of calcium to phosphorus in bone (2.3:1) and adds to this figure that of the phosphorus equivalent of the extra nitrogen excretion $(+$ or - ) derived from the proportion of nitrogen to phosphorus in protein $(17.4: 1)$ the result is near that actually found for increased phosphorus excretion. In 
other words, the phosphorus balance varies with the phosphorus equivalents of the calcium and nitrogen balances $(24,25)$. The only notable departure from this generalization was that on administration of large amounts of acid, (e.g. DA Case II, periods XIV and XV) there was, at the time of the diuresis and loss of weight, a prompt increase in the phosphorus of the urine out of proportion to the change in the excretion of calcium and nitrogen. In the after-period there was a similar retention of phosphorus so that while the calcium excretion remained above basal levels for several days after the last dose of $\mathrm{NH}_{4} \mathrm{Cl}$, the phosphorus of the urine dropped promptly to less than that of the control periods. The final net balance, justifies the original statement.

\section{The effect of ingestion of excess alkali}

It was found impossible to devise a palatable low calcium diet that had a large potential alkalinity. Accordingly, varying amounts of sodium bicarbonate and sodium citrate were fed in order to observe the effect of ingestion of excess alkali on the excretion of calcium and phosphorus. In Case I the ingestion of 9 grams of $\mathrm{NaHCO}_{3}$ and 6 grams of sodium citrate per day produced no effect on the calcium content of either urine or stools. In Case II there was possibly a slight increase and in Case III a definite slight increase in urinary calcium, but no increase in the calcium of the feces, when very large amounts of alkali (12 grams of $\mathrm{NaHCO}_{3}$ and 12 grams sodium citrate daily) were taken. In no instance, however, did ingestion of excess alkali have any important effect on the calcium or phosphorus balance.

\section{Serum values}

It has been found that when blood is taken from normal, fasting individuals the serum calcium may remain remarkably constant over considerable periods of time, the serum phosphorus being slightly more variable (26). In this investigation also, there was very little change in the levels of serum calcium and phosphorus. In some patients, however, (DA, Case II, period XV; ST, Case III, period XIII), who had been for a long time on a low calcium diet, the administration of large amounts of $\mathrm{NH}_{4} \mathrm{Cl}$ seemed to cause a definite fall in both the calcium and inorganic phosphorus of the fasting blood. The serum protein 
changed relatively little but the $\mathrm{CO}_{2}$ content of the plasma fell definitely after ingestion of 4 to 6 grams of $\mathrm{NH}_{4} \mathrm{Cl}$ and markedly after ingestion of larger amounts of $\mathrm{NH}_{4} \mathrm{Cl}$. It is to be noted that the great increase in calcium excretion, which occurred on ingestion of large amounts of $\mathrm{NH}_{4} \mathrm{Cl}$, was not associated with an increase in the serum calcium level.

\section{Effect of ketogenic diet}

The calcium and phosphorus excretion was followed in LN (Case V), a child of 7 years of age, who was given a ketogenic diet for the treatment of epilepsy by Dr. Harold Higgins. The diet throughout was approximately neutral and was well taken by the child, who was happy and cooperated willingly. Results are presented in table 6.

As the ratio of fat to carbohydrate and protein in the diet was increased, there developed a marked ketosis and an initial loss of weight (due to loss of body water). With this acidosis there was an increase in the urine calcium excretion so that the calcium balance changed from being definitely positive to distinctly negative. The phosphorus balance also became negative. These results are similar to those reported by Nelson (13) and by Sawyer, Baumann and Stevens (14).

\section{The effect of ingestion of excess acid when the serum calcium is abnormally low}

All the results discussed so far were obtained on subjects believed to have an essentially normal calcium metabolism. In the course of our investigation there arose an opportunity of studying the effect of similar measures in a patient with an abnormally low serum calcium. Mrs. DB, age 27, weight 43 kilos, had suffered for four years from tetany associated with deranged fat absorption. Her history and the detailed results of the investigation are described in another paper (27).

In table 7 are presented data showing the average values for groups of periods in which she was given first a low calcium, then a higher calcium diet; and, while on the higher calcium diet, 4 grams $\mathrm{NH}_{4} \mathrm{Cl}, 6$ grams $\mathrm{NH}_{4} \mathrm{Cl}$, and 9 grams $\mathrm{CaCl}_{2}$ daily, respectively. On the low calcium diet the calcium excretion in the urine was exceedingly smallso little in fact that it could scarcely be measured; nor did it rise on 


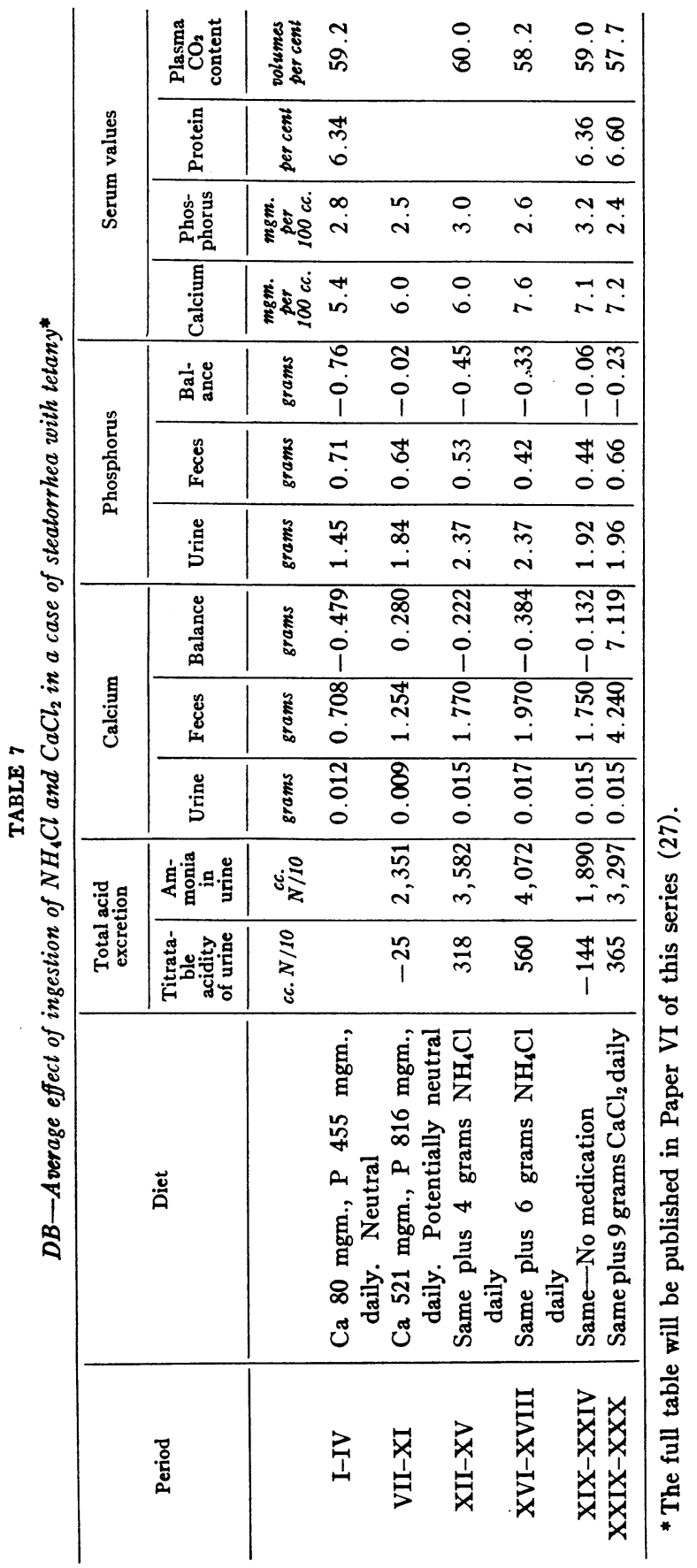


ingestion of higher calcium diet, $\mathrm{NH}_{4} \mathrm{Cl}$ or $\mathrm{CaCl}_{2}$. The fecal calcium on the other hand was unusually high so that for most of the time there was a negative calcium balance. The proportion of phosphorus excreted in the urine was within normal limits. Associated with the negative calcium balance there was a negative phosphorus balance.

Although ingestion of potential acid resulted in great increase in ammonia production, yet in contrast to those cases with normal serum calcium the urinary calcium output was not increased: even when the serum calcium rose from about 5 to about $7 \mathrm{mgm}$. there was no change in the urinary excretion. That the low calcium excretion of this patient was not entirely dependent on the low serum calcium is shown by observations previously made (27) on a case of postoperative tetany, in which administration of $\mathrm{NH}_{4} \mathrm{Cl}$ resulted in a distinct increase of calcium in the urine. In the postoperative patient, however, the initial urinary calcium was much higher and presumably body stores were much greater. In our patient the factors limiting urinary calcium excretion were such that the calcium excretion was too little to be measured with accuracy.

\section{SUMMARY}

The effect of large variation in the acid-base balance as brought about by ingestion of ammonium chloride, sodium bicarbonate and sodium citrate and of potentially acid and ketogenic diets, has been studied in a number of patients on a fixed low-calcium diet and in one patient receiving a higher calcium diet.

The calcium excretion was found to vary with the total excess acid eliminated and more particularly with the output of ammonia, and appeared to be independent of the reaction of the urine.

The quantitative increase in calcium excretion in response to ingestion of acid was greatly influenced by the basal level of calcium excretion as well as by the amount of excess acid ingested.

The increased calcium excreted played a very small rôle in balancing excess acid output, even though the calcium of the urine was increased many times above the basal.level.

Calcium elimination was only slightly affected by large doses of alkali. 
On low-calcium diet the fecal calcium remained nearly constant despite great changes in the potential acidity of the diet.

In one patient with steatorrheic tetany and persistently low serum calcium, administration of higher calcium diet, $\mathrm{NH}_{4} \mathrm{Cl}$ and $\mathrm{CaCl}_{2}$, failed to cause an increased output of calcium in the urine.

\section{BIBLIOGRAPHY}

1. McClendon, J. F., Am. J. Physiol., 1922, lxi, 373. Calcium Phosphate Metabolism in the Diagnosis of Rickets.

2. Zucker, T. F., Johnson, W. C., and Barnett, M., Proc. Soc. Exp. Biol. and Med., 1922-3, xx, 20. The Acid-Base Ratio of the Diet in Rickets Production.

3. Givens, M. H., and Mendel, L. B., J. Biol. Chem., 1917, xxxi, 421. Studies in Calcium and Magnesium Metabolism. I. The Effects of Base and Acid.

4. Givens, M. H., J. Biol. Chem., 1917, xxxi, 43.5. Studies in Calcium and Magnesium Metabolism. II. The Effect of Diets Poor in Calcium.

Givens, M. H., J. Biol. Chem., 1918, xxxv, 241. V. Further Observations on the Effect of Acid and Other Dietary Factors.

5. Goto, King, J. Biol. Chem., 1918, xxxvi, 355. Mineral Metabolism in Experimental Acidosis.

6. Lamb, A. R., and Evvard, J. M., J. Biol. Chem., 1919, xxxvii, 317. The Acid-Base Balance in Animal Nutrition. I. The Effect of Certain Organic and Mineral Acids on the Growth, Well Being, and Reproduction of Swine.

Lamb, A. R., and Evvard, J. M., J. Biol. Chem., 1919, xxxvii, 329. II. Metabolism Studies on the Effect of Certain Organic and Mineral Acids on Swine.

7. Shohl, A. T., and Sato, A., J. Biol. Chem., 1923, lviii, 257. Acid-Base Metabolism. II. Mineral Metabolism.

8. Zucker, T. F., Proc. Soc. Exp. Biol. and Med., 1921, xviii, 272. The Relation of Acid-Base Equilibrium in the Body to Excretion of Phosphorus and Calcium.

9. Fiske, C. H., and Sokhey, S. S., J. Biol. Chem., 1925, lxiii, 309. Ammonia and Fixed Base Excretion after the Administration of Acid by Various Paths.

10. Fiske, C. H., Goodell, R. A., Hathaway, L. E., Jr., and West, E. J., J. Biol. Chem., 1926, lxvii, 385. Further Observations on the Fate of Acid in the Body.

11. Stehle, R. L., and McCarty, A. C., J. Biol. Chem., 1921, xlvii, 315. The Effect of $\mathrm{HCl}$ Ingestion upon the Composition of the Urine in Man.

12. Bogert, L. J., and Kirkpatrick, E. E., J. Biol. Chem., 1922, liv, 375. Studies in Inorganic Metabolism. II. The Effects of Acid-Forming and BaseForming Diets upon Calcium Metabolism. 
13. Nelson, Martha V., Am. J. Dis. Child., 1928, xxxvi, 716. Calcium and Phosphorus Metabolism of Epileptic Children Receiving a Ketogenic Diet.

14. Sawyer, M., Baumann, L., and Stevens, F., J. Biol. Chem., 1918, xxxiii, 103. Studies of Acid Production. II. The Mineral Loss During Acidosis.

15. Kylin, E., Acta Med. Scandinav., 1927, lxvi, 197. Über den Kalkumsatz bei Diabetes Mellitus.

Meyer-Bisch, R., Ergebn. d. inn. Med. u. Kinderh., 1927, xxxii, 267. Mineral und Wasserstoff wechsel bei Diabetes mellitus.

16. Benedict, F. G., Carnegie Institution of Washington, Pub. 203, 1915. A Study of Prolonged Fasting.

17. Bauer, W., Albright, F., and Aub, J. C., J. Clin. Invest., 1929, vii, 75. Studies of Calcium and Phosphorus Metabolism. II. The Calcium Excretion of Normal Individuals on a Low Calcium Diet, Also Data on a Case of Pregnancy.

18. Bauer, W., and Aub, J. C., J. Am. Dietetic Assoc., 1927, iii, 106. Studies of Inorganic Salt Metabolism. I. The Ward Routine and Methods.

19. Fiske, C. H., J. Biol. Chem., 1925, lxv, 101. Unpublished Method, first described in paper by Hamilton, $B$.

20. Farquharson, R. F., Salter, W. T., and Aub, J. C., J. Clin. Invest., 1931, x, 251. Studies of Calcium and Phosphorus Metabolism. XIII. The Effect of Ingestion of Phosphorus on the Excretion of Calcium.

21. Gamble, J. L., Ross, G. S., and Tisdall, F. F., J. Biol. Chem., 1923, lvii, 633. The Metabolism of Fixed Base During Fasting.

22. Salter, W. T., and Farquharson, R. F., To be published. Observations on Urinary Acid and Ammonia Excretion with Controlled Diet.

23. Gamble, J. L., Blackfan, K. D., and Hamilton, B., J. Clin. Invest., 1924-25, i, 359. A Study of the Diuretic Action of Acid-Producing Salts.

24. Aub, J. C., Bauer, W., Heath, C., and Ropes, M., J. Clin. Invest., 1929, vii, 97. Studies of Calcium and Phosphorus Metabolism. III. The Effects of the Thyroid Hormone and Thyroid Disease.

25. Albright, Fuller, Bauer, W., Ropes, M., and Aub, J. C., J. Clin. Invest., 1929, vii, 139. Studies of Calcium and Phosphorus Metabolism. IV. The Effect of the Parathyroid Hormone.

26. Farquharson, R. F., and Tibbetts, D. M., J. Clin. Invest., 1931, x, 271. Studies of Calcium and Phosphorus Metabolism. XVIII. On Temporary Fluctuations in the Level of Calcium and Inorganic Phosphorus in Blood Serum of Normal Individuals.

27. Aub, Joseph, Albright, Fuller, and Bauer, Walter, To be published. Studies of Calcium and Phosphorus Metabolism. VI. In Various Types of Tetany. 